\title{
A STRONG VARIATION OF ACCRETION DISC CORONA SIZE WITH LUMINOSITY IN LMXB
}

\author{
M. J. Church ${ }^{1,2}$ \\ RESUMEN
}

Se revisa la controversia que ha existido durante años sobre la naturaleza del continuo de rayos $\mathrm{X}$ emitido por la binarias de rayos- $\mathrm{X}$, y que ha estado polarizada entre el modelo oriental con una pequeña región afectada por efecto Compton rodeando el objeto compacto y otros modelos alternativos. Presentamos medidas de la extensión radial de esta región $\mathrm{ADC}$ en binarias de rayos $\mathrm{X}$ de baja masa, las cuales excluyen este modelo oriental y muestran que la región ADC es extensa (modelo Birmingham), mostrando los tiempos de ingresos profundos de una manera concluyente que la extensión radial de la zona ACD varía desde el $7 \%$ del radio del disco de acreción en fuentes débiles, hasta el $65 \%$ en fuentes brillantes. Hay que señalar que el tamaño depende fuertemente do la luminosidad de la fuente, lo cual sugiere que la zona ADC se forma por irradiación del disco por la estrella de neutrones y el disco interno caliente. Estos resultados tienen implicaciones fundamentales para la correcta descripción del proceso de "Comptonización" en las binarias de rayos X, la cual difiere sustancialmente de la del modelo oriental. Las medidas de las temperaturas electrónicas de la ADC nos proporcionan valores del radio de Compton en buena consonancia con los valores medidos de la extensión radial de la ADC. Finalmente, mostramos que los resultados son inconsistentes con una emisión no térmica producida en un "jet" y por tanto proporcionan evidencia en contra de la reciente sugerencia de que todos los LMXB tienen "jets".

\section{ABSTRACT}

The controversy that has existed for many years over the nature of the continuum X-ray emission components in X-ray binaries is reviewed, in which workers have been polarized between the Eastern model with a small central Comptonizing region around the compact object and alternative models. We present measurements of the radial extent of the Comptonizing $\mathrm{ADC}$ in low mass X-ray binaries which rule out the Eastern model and show that the ADC is extended (the Birmingham model). Dip ingress timing shows conclusively that the ADC radial extent varies from $7 \%$ of the accretion disc radius in faint sources, to $65 \%$ in bright sources. Remarkably, the size depends strongly on the source luminosity suggesting that the ADC is formed by irradiation of the disc by the neutron star and the hot inner disc. These results have fundamental implications for the correct description of Comptonization in X-ray binaries, and the spectral form is derived for the Comptonized emission of an extended ADC fed by soft seed photons from the underlying disc which differs substantially from that of the Eastern model. Measured ADC electron temperatures provide values of the Compton radius in broad agreement with measured values of the radial extent of the ADC. Finally, we show that the results are inconsistent with the non-thermal emission being produced in a jet, and so provide evidence against the recent suggestion that all LMXB have jets.

\section{Key Words: HII REGIONS - ISM: JETS AND OUTFLOWS}

\section{INTRODUCTION}

A major problem which has impeded understanding of Low Mass X-ray Binaries containing neutron stars over many years has been the controversy over the location and nature of the X-ray emission regions. Two radically different descriptions were developed in the mid-1980s, the Western model and the Eastern model. In the West-

\footnotetext{
${ }^{1}$ School of Physics \& Astronomy, University of Birmingham, Birmingham B15 2TT, UK (mbc@star.sr.bham.ac.uk).

${ }^{2}$ Astronomcal Observatory, Jagiellonian University, ul Orla 171, 30-244 Cracow, Poland.
}

ern model, the dominance of Comptonization in the spectra of LMXB was described with the Generalised Thermal model having the form of a power law, cut off at high energies corresponding to the energy limit of Comptonizing electrons (White, Stella \& Parmar 1988). The Eastern model assumes multitemperature blackbody emission from the inner disc, plus emission from the neutron star providing the seed photons for the observed Comptonized emission (Mitsuda et ai. 1989). Comptonization is assumed to take place either in the atmosphere of the neutron star or in a small, central region containing hot elec- 
trons. Both Western and Eastern model were able to prove good fits to the spectra of LMXB, and so could not be discriminated between on this basis. In the 1990s, there was increasing evidence that two emission components were present in all sources, whereas the Western model only needed a second component in bright sources. A new model (the Birmingham model) closely related to the Western model was proposed in which two continuum components exist in all LMXB, simple blackbody emission from the neutron star plus Comptonized emission from an extended accretion disc corona (ADC) above the accretion disc (Church \& Batucińska-Church 1995). Clearly, the physical descriptions contained in the Birmingham model and the Eastern model are radically different (see Fig. 1) and the failure to resolve which model is correct has been a major impediment to understanding.

The Eastern model is extensively used, for example, theoreticians have in general considered it natural that the Comptonizing region will be located close to the neutron star and so have supported the Eastern model (e.g. Kluzniak \& Wilson 1991).
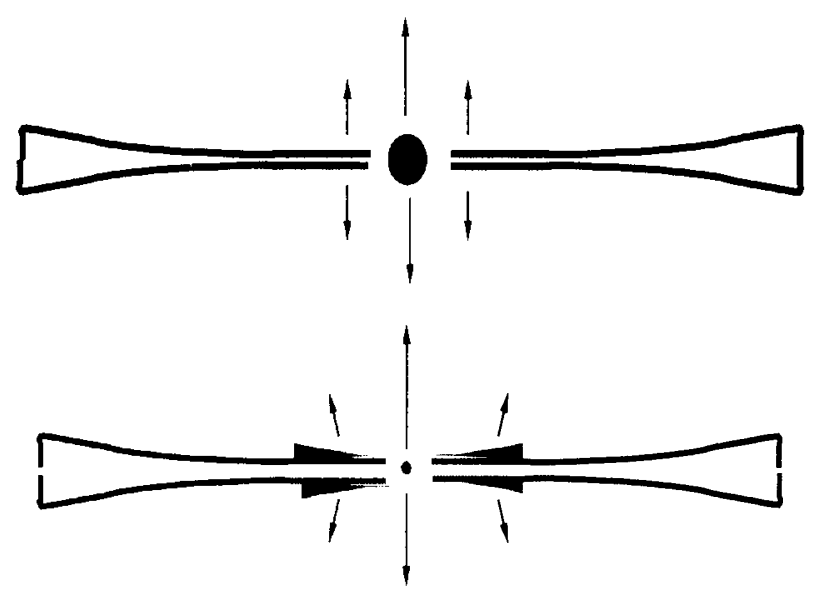

Fig. 1. Upper panel: the Eastern model; lower panel: the Birmingham model

In fact, the key to resolving the controversy of the correct emission model has lain with the dipping LMXB which provide more diagnostics of the emission regions that non-dipping sources and more strongly constrain spectral models. These sources having inclination angle between $65^{\circ}$ and $85^{\circ}$ exhibit orbital-related X-ray dips due to absorption in the bulge in the outer disc (White \& Swank 1982). Application of the Birmingham model provided substantial evidence that the blackbody component was present in all sources in varying degrees. Over a pe- iiod of years it has been shown that the model provides very good fits to all of the $\sim 10$ dipping sources (e.g. Church et al. $(1997,1998)$ : Bałucińska-Church et al. (2000); Church \& Bałucińska-Church (1995). It also fits well the Atoll and Z-track sources included in an $A S C A$ survey of LMXB (Church \& BałucińskaChurch 2001) showing that the model describes well all classes of LMXB.

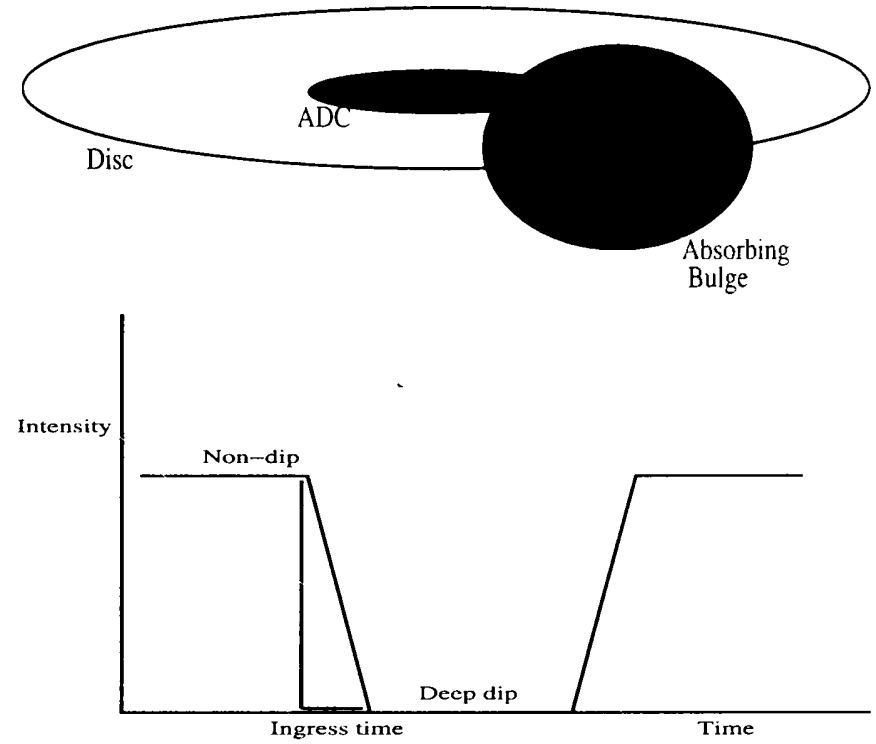

Fig. 2. Upper panel: geometry of ADC; lower panel: dip ingress time depends on $\mathrm{ADC}$ size

Fig. 2 shows the geometry of a LMXB with the extended accretion disc corona of radial extent $r_{\mathrm{ADC}}$ above a thin accretion disc, and the bulge in the outer disc where the accretion flow from the companion star impacts, which is responsible for X-ray dipping. The upper diagram shows the view at a large inclination angle $\left(\sim 75^{\circ}\right)$ typical of dipping sources. The angular size of the absorber is larger than that of the ADC so that dipping will be $100 \%$ deep. in which case the ingress time $\Delta t$ shown in the lower diagram depends on the angular extent of the ADC:

$$
\begin{gathered}
\frac{2 \pi r_{\mathrm{AD}}}{P}=\frac{2 r_{\mathrm{ADC}}}{\Delta t} \quad \text { or } \quad r_{\mathrm{ADC}}=\pi r_{\mathrm{AD}} \frac{\Delta t}{P} . \\
\text { 2. RESULTS }
\end{gathered}
$$

\section{RESULTS}

The observations selected consist primarily of data obtained using the satellites ASCA. Rosat. BeppoSAX and Rossi-XTE previously analysed by us in detail. Spectral fitting results previously obtained by us were used to provide the source fluxes in the band $1.30 \mathrm{keV}$. In Fig. 3, we show the variation of ADC radial extent with $L_{\text {Tot }}$.

Fig. 3 displays two significant results: it confirms that the ADC is very extended as is also apparent 


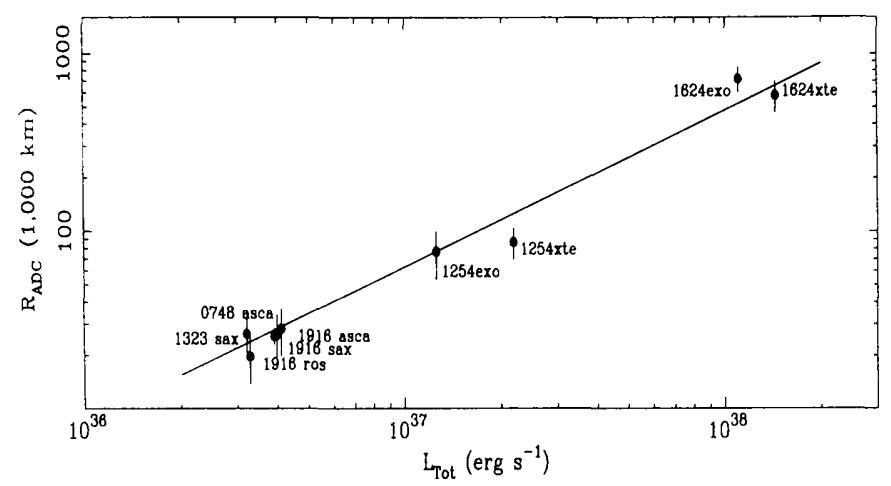

Fig. 3. Variation of ADC radial extent with luminosity

from spectral fitting of dip spectra (Sect. 1), and secondly, there is a strong correlation between $r_{\mathrm{ADC}}$ and somec luminosity. The extended ADC varies between a minimum of $\sim 7 \%$ of the accretion disc radius to a maximum of $65 \%$ (in X 1624-490). These results have consequences for LMXB emission models, for the correct description of Comptonization and for models of ADC formation as discussed below.
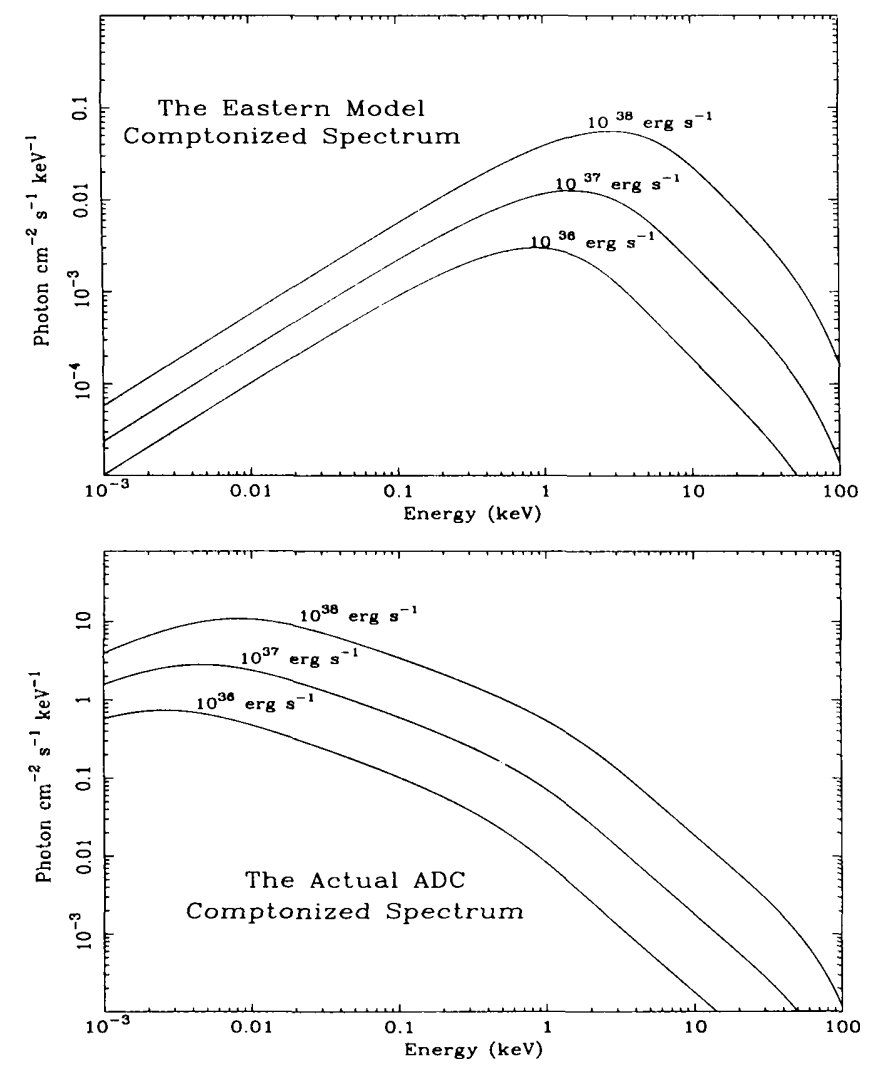

Fig. 4. Comparison of C'omptonized emission in the Fasitern and Birmingham models

\section{DISCUSSION}

There are two major consequences of the result.s: firstly the extended ADC size does not allow the pos- sibility of the Eastern model in which Comptonization is assumed to take place in a central region associated with the neutron star or inner disc. The radius of such a region would be of order $\$ 100 \mathrm{~km}$, which is 500 times smaller than measured here. Secondly, Comptonization is strongly dependent on the size of the ADC, and the seed photons generated in the disc below the extended ADC will be very soft, contrasting with the $1 \mathrm{keV}$ seed photons assumed in the Eastern model.

Fig. 4 shows the Comptonized spectra calculated for the Eastern model and for an extended ADC covering the inner $15 \%$ of the accretion disc. In the first case, the seed photons are assumed to have simple blackbody form from the neutron star or inner disc with $k T \sim 1 \mathrm{keV}$ (Done et al. 2002). The strong differences between the models can be seen. In particular, the actual ADC does not exhibit a low-energy cut-off as in the Eastern model at a few keV, and the exact shape of the high energy cut-off also differs between the two models which will be relevant in fitting X-ray data.

The results also relate to the formation of the ADC which has been poorly understood or controverial. In general there have been two classes of models proposed: internal mechanisms within the accretion disc (for example: Liang \& Price (1977); Paczyński (1978); Galeev, Rosner \& Vaiana (1979); also hot-disk models (Shapiro, Lightman \& Eardley 1976; Zdziarski 1998). However, there have also been models based on irradiation by the central source ( Fabian, Guilbert \& Ross (1982); Begelman, McKee \& Shields (1983); Różańska \& Czerny 1996; JimenezGarate, Raymond \& Liedahl (2002); Proga \& Kallman 2002). The present work clearly supports the modelling in which a very extended ADC is formed by illumination of the disc by the central source. In a full description of the results (Church \& BalucińskaChurch 2004), we show that there is limited evidence for the ADC size to be limited to the Compton radius: the maximum radius for hydrostatic cquilibrium. Analysis of broadband BeppoSAX spectra allowed the electron temperature to be derived in several cases, and so the Compton radius $G M m / k T$ calculated. Further comparison with theory is necestary as the modelling treatments normally do not include the radial dependence, only the vertical dependence of $\mathrm{ADC}$ properties.

Finally, the results are relevant to the suggestion that all $\mathrm{X}$-ray binaries may have jets, including L AIXB (Fender 2003). The suggestion was made that the power law emission in LMXB may be synchrotron emission from a jet, not Comptonization. 
However, our demonstration that the $\mathrm{ADC}$ is very extended, and also thin, not extending high above the disc (Smale et al. 2001) is inconsistent with jet geometry. This removes the argument for jets to be present in general in LMXB.

\section{REFERENCES}

Bałucińska-Church, M., Humphrey, P. J., Church, M. J., Parmar, A. N., 2000, A\&A, 360, 583

Begelman, M. C., McKee, C. F., Shields, G. A., 1983, ApJ, 271, 70

Church, M. J., Bałucińska-Church, M., 1995, A\&A, 300, 441

Church, M. J., Bałucińska-Church, M., 2001, A\&A, 369, 915

Church, M. J., Bałucińska-Church, M., 2004, MNRAS, in press; astro-ph/0309212

Church, M. J., Dotani, T., Balucińska-Church, M., et al., 1997, ApJ, 491, 388

Church, M. J., Balucińska-Church, M., Dotani, T., Asai, K., 1998, ApJ, 504, 516

Done, C., Życki, P. T., Smith, D. A., 2002, MNRAS, 331, 453
Fabian, A. C., Guilbert, P. W., Ross, R. R., 1982. MNRAS, 199, 1045

Fender, R., in "Compact Stellar X-ray Sources". eds. W H. G. Lewin, M. van der Klis, Cambridge Lniversity Press, 2003

Galeev, A. A., Rosner, R., Vaiana, G. S. 1979. ApJ. 229. 318

Jimenez-Garate, M. A., Raymond, J. C.., Liedahl, D. A.. 2202, ApJ, 581, 1297

Kluźniak, W., Wilson, J. R., 1991, ApJ 327, L87

Liang, E. P. T., Price, R. H., 1997, Ap.J, 218, 247

Mitsuda, K., Inoue, H., Makamura, N.. Tanaka. Y., 1989. PASJ, 41,97

Paczyński, B., 1978, Acta Astron, 28, 241

Różańska, A., Czerny, B., 1996, Acta Astron., 46, 223

Proga, D., Kallman, T. R., 2002, ApJ, 56i5, 455

Shapiro, S. L., Lightman, A. P., Eardley, D. M.. 1976. ApJ, 204, 187

Smale, A. P., Church, M: J., Bałucińska-Church, N.. 2001, ApJ, 550, 962

White, N. E., Swank, J. H., 1982, ApJ, 253, L61

White, N. E., Stella, L., Parmar, A. N., 1988, ApJ. 324. 363

Zdziarski, A. A., 1998, MNRAS, 296, L51 